\title{
Adolescente em cumprimento de medida socioeducativa de semiliberdade: seu perfil no Distrito Federal
}

\section{Profile of adolescent offenders in correctional semi-liberty facilities in the Federal District (DF) of Brazil}

\author{
Elessandra da Silva Cruz* \\ Bernardo Kipnis* \\ Alcyone Vasconcelos ${ }^{* \star}$
}

\begin{abstract}
Resumo: $O$ presente artigo descreve o perfil do adolescente em cumprimento de medida socioeducativa de semiliberdade no Distrito Federal (DF). Utilizou-se abordagem de natureza quantitativa, a partir do levantamento de dados secundários coletados nos registros eletrônicos das seis unidades de semiliberdade do DF que são inseridos no SIPIA. As análises referentes às variáveis idade, sexo, etnia, escolaridade, situação profissional, convívio familiar, bairro de residência, renda familiar e uso de drogas são apresentadas relacionando os resultados a outras pesquisas e à literatura atual sobre o assunto. Como resultados, observou-se que a maioria dos adolescentes em semiliberdade no DF é de afrodescendentes, que se encontram matriculados em instituição de ensino, com distorção na relação idade/série escolar, não trabalham, são oriundos de famílias chefiadas por mulheres e possuem residência nas regiões administrativas de Planaltina, Ceilândia e Sobradinho do Distrito Federal. Cenário este coincidente com estudo realizado 10 anos antes, indicando ter havido pouca mudança em termos do perfil desse público analisado.
\end{abstract}

Palavras-chave: Adolescente. Medida Socioeducativa de Semiliberdade. Perfil do Adolescente em cumprimento de medida de semiliberdade.

\footnotetext{
* Mestranda em Política Públicas e Gestão da Educação pela Universidade de Brasília. Especialista em Políticas Públicas e Socioeducação pela UnB. Licenciada em Letras pela Universidade de Brasília e em Pedagogia pelo Centro Universitário Internacional (UNINTER). E-mail: ele.c.silva@gmail.com

** Doutor em Comparative Education - University of London. Pós doutorado na University of California, Berkeley, como bolsista CAPES. Pós-doutorado em Monash University, Austrália, como bolsista CAPES. Mestre em Economia pela Universidade de Brasília. Graduado em Economia pela Universidade do Estado do Rio de Janeiro. Professor associado da Universidade de Brasília. Faculdade de Educação e Diretor do Centro de Estudos Avançados em Governo e Administração Pública. E-mail: bernardo.kipnis@gmail.com

*** Doutora em Administração da Educação pela Illinois State University. Professora da Universidade de Brasília - Faculdade de Economia, Administração e Contabilidade. E-mail: alcyone.v@gmail.com
}

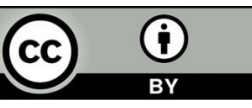

This content is licensed under a Creative Commons attribution-type BY 


\begin{abstract}
This paper describes the profile of adolescent offenders in correctional semi-liberty facilities in the Federal District (DF) of Brazil. A quantitative approach was used to analyze secondary electronic data collected from the System Information for the Childhood and Adolescence (SIPIA) about the six semi-liberty facilities in the DF. The variables of age, gender, ethnicity, education, work status, family life, district of residence, family income, and drug use were analyzed in comparison to the results from other studies and the current literature. The findings suggest that most of the adolescents in semiliberty facilities in the DF are afro-descendants, are enrolled in educational institutions, have delayed school achievement, do not work, belong to femaleheaded single-parent families, and live in the districts of Planaltina, Ceilândia, and Sobradinho. This scenario coincides with the one described by a study carried out 10 years earlier, which indicates that the profile of this public has not changed much.
\end{abstract}

Keywords: Adolescent offenders. Correctional service of semi-liberty. Profile of adolescents in semi-liberty facilities.

Recebido em 24/04/2020. Aceito em 15/05/2020

\title{
Introdução
}

O Estatuto da Criança e do Adolescente (ECA) simboliza um grande avanço no ordenamento jurídico brasileiro. Considerado o maior instrumento normativo nacional que trata dos direitos de crianças e adolescentes, trouxe questões fundamentais - uma delas foi o reconhecimento de crianças e adolescentes como sujeitos de direitos, respeitando a condição peculiar de pessoa em desenvolvimento.

Outro marco trazido pelo ECA refere-se a um capítulo específico que trata do adolescente que cometeu ato infracional. Como adolescente a lei entende uma pessoa entre 12 e 18 anos incompletos, e como ato infracional entende-se a conduta descrita em lei como crime ${ }^{1}$ ou contravenção penal'2.

Como sanção à prática do ato infracional, após a apuração por devido processo legal da responsabilidade do adolescente, o estatuto propõe as seguintes medidas socioeducativas³:

\footnotetext{
${ }^{1}$ Crime: "fato típico e antijurídico, a que a lei comina pena de reclusão ou de detenção, quer isoladamente, quer alternativa ou cumulativamente com a pena de multa" (RABESCHINI, 2014, n.p.).

${ }^{2}$ Contravenção penal: “a infração penal a que a lei comina pena de prisão simples ou de multa, ou ambas, alternativa ou cumulativamente” (RABESCHINI, 2014, n.p.).

${ }^{3}$ A medida socioeducativa de advertência trata-se de uma medida socioeducativa admoestatória e imediata executada pelo Juiz da Infância e Juventude; medida socioeducativa de obrigação de reparar o dano ocorre quando o juiz determina que o adolescente restitua a coisa, compense o prejuízo da vítima; a medida socioeducativa de prestação de serviço à comunidade caracteriza-se pelo apelo comunitário, envolvendo no processo uma reflexão por parte do infrator e da comunidade; a medida socioeducativa de liberdade assistida consiste no acompanhamento, auxílio e orientação de uma equipe de especialistas para o adolescente, sem privá-lo de sua liberdade nem de seu convívio familiar e comunitário; a medida socioeducativa de internação priva o adolescente de liberdade por um prazo que varia de seis meses até três anos (BRASIL, 1990).
} 
advertência, obrigação de reparar o dano, prestação de serviços à comunidade, liberdade assistida, semiliberdade e internação. Não há uma regra fixa que determine o juiz a aplicar determinada medida socioeducativa conforme determinado ato infracional cometido (FIGUEIREDO; FRASSETO, 2015). Este trabalho está focado, especificamente, no adolescente em cumprimento de medida socioeducativa de semiliberdade.

A medida socioeducativa de semiliberdade é considerada por Fuchs (2009) como uma sanção do Estado ao adolescente em conflito com a lei que restringe a sua liberdade. Mais branda que a medida de internação, nesse tipo de sanção o adolescente, mesmo em custódia do Estado, é autorizado a realizar atividades externas à unidade (escolarização e profissionalização) e assim como nas demais medidas socioeducativas, a manter o convívio familiar. Para tratar do adolescente em conflito com a lei se faz necessário compreender que não se está diante de infratores ${ }^{4}$ que, por acaso, são adolescentes, mas diante de adolescentes que, por diferentes circunstâncias, se envolveram na prática de atos infracionais (COSTA, 2004).

Buscando compreender o universo no qual o adolescente em cumprimento de medida socioeducativa de semiliberdade está inserido, a partir de um levantamento preliminar foram identificados estudos delimitados geograficamente a outras unidades federativas que não ao Distrito Federal. Dos trabalhos encontrados, destaca-se: a tese de Gallo (2006) que levantou o perfil de adolescentes em prestação de serviço à comunidade e liberdade assistida no município de São Carlos (SP); os trabalhos de Zappe e Ramos (2010) e de Nardi et al. (2014) que traçaram o perfil do adolescente em medida socioeducativa de internação nos municípios de Santa Maria e Porto Alegre (RS); a dissertação de Araújo (2004) que levantou o perfil das adolescentes que cumpriram medida socioeducativa de internação em Salvador (BA); e a tese de Fuchs (2009) que buscou traçar o perfil do adolescente em cumprimento de semiliberdade no Brasil.

Sobre os adolescentes privados de liberdade em regime de semiliberdade, o presente estudo busca refletir sobre quem são, de onde vêm e que fatores de vulnerabilidade podem ser encontrados a partir da análise de seu perfil. Conhecer o perfil desse adolescente, em uma perspectiva sociocultural, considerando que o ser humano se constitui na interação com outros indivíduos e com o meio social no qual está inserido, permite aproximar de suas realidades e romper os mitos do imaginário popular sobre quem são esses jovens (ZAPPE; RAMOS, 2010; PAES, 2015).

É importante ressaltar que este estudo não pretende realizar uma investigação explicativa sobre a criminalidade juvenil no Distrito Federal, mas ampliar as informações acerca do perfil socioeconômico do adolescente autor de ato infracional que cumpre medida de semiliberdade no Distrito Federal. Para isso descreve-se o perfil dos adolescentes que cumprem medida de semiliberdade nas seis Unidades de atendimento de semiliberdade do Distrito Federal, a partir de variáveis quantitativas presentes no banco de dados das unidades e registradas no Sistema para Infância e Adolescência (SIPIA) e, quando apropriado, do seu cruzamento.

Destaca-se que, apesar de alguns textos utilizarem o termo delinquência juvenil para tratar do adolescente envolvido com quadros de violência, crimes e/ou contravenções, esse termo demonstra uma condição de um estágio estável e duradouro, entendimento que contradiz os conceitos socioculturais de desenvolvimento humano. Para o desenvolvimento dessa pesquisa optou-se por utilizar o termo adolescente em conflito com a lei ${ }^{5}$, ou adolescente em cumprimen-

\footnotetext{
${ }^{4}$ Optou-se pela utilização a palavra infrator, conforme foi utilizada pelo autor citado.

${ }^{5}$ Termos como a expressão 'de menor' carregam a ideia da exclusão social marcada nos extintos Códigos de Menores. A substituição do termo ‘de menor’ para adolescente em conflito com a lei demarca uma mudança de paradigma ocorrida nas políticas públicas, destinadas ao público infanto juvenil nos últimos anos, considerando esses indivíduos como sujeitos de direitos. Essa terminologia também está mais "alinhada com os paradigmas preconizados pelas normas de direito internacional e nacional” (Agência de Notícias dos Direitos da Infância - ANDI, [s.d.]).
} 
to de semiliberdade, em detrimento de expressões como 'de menor', 'adolescente infrator' ou delinquência juvenil.

O artigo se encontra estruturado em duas seções de discussão teórica sobre desenvolvimento humano, vulnerabilidade, fatores de risco e proteção; seguidos de uma seção destinada às considerações metodológicas do estudo realizado; por uma seção de análise e discussão dos resultados; e finalizado com considerações finais, tendo como conclusão que o perfil do adolescente em cumprimento de semiliberdade no DF é um recorte classista e racista no qual predominam afrodescendentes, pobres de baixa escolaridade, residentes em localizações distintas - nas quais estão localizadas as unidades de atendimento, e oriundos de famílias chefiadas por mulheres.

\section{Desenvolvimento humano e adolescência}

A adolescência, ao longo do tempo, foi interpretada como uma etapa do desenvolvimento humano em que a criança caminhava para a vida adulta, como um estágio marcado por modificações corporais e transformações no comportamento. Diante dessa visão, adolescência era considerada um fenômeno natural de crescimento biológico, um "período de transição entre a infância e a vida adulta, caracterizado pelos impulsos do desenvolvimento físico, sexual e emocional" (EISENSTEIN, 2005, p. 6).

Em discordância, e como alternativa de argumentação na perspectiva sociocultural, entende-se que o desenvolvimento do corpo humano não é um processo isolado, mas sim corresponde à ação adaptativa do organismo à pressão ou coação de um ou mais fatores interdependentes, originários do contexto, associando-se às expectativas sociais que marcam diferentes fases da vida e aos contextos de interação e instituições (OLIVEIRA, 2016, SOUZA et al., 2014).

Um dos precursores dessa transição de pensamento foi o psicólogo bielo-russo Lev Semyonovich Vygotsky (1896-1934). Importante teórico do desenvolvimento humano, ele apresentou uma visão inovadora de tal processo, contrariando o modelo linear, predominante na psicologia da época, por meio da abordagem histórico-cultural (ARAÚJO; OLIVEIRA, 2010; SOUZA, 2016). O princípio que orienta esta abordagem é o de que desde o nascimento, a partir das interações com o grupo, o indivíduo se apropria dos significados construídos socialmente, sendo os aspectos culturais e históricos influenciadores do desenvolvimento humano.

A partir da perspectiva histórico-cultural as mudanças corporais, típicas das fases etárias de desenvolvimento, deixam de ser vistas de forma isolada e passam a ser associadas a mudanças de comportamento e à aquisição de autonomia. Esses fatores somados influenciam a formação do adolescente (SOUZA, 2016).

A partir da abordagem histórico-cultural, Vygotsky adotou a linha de desenvolvimento humano sociocultural, na qual o ser humano "se constitui de modo interdependente do contexto social, cultural e histórico, a partir da sua participação em sistemas concretos de atividades sociais, mediadas por instrumentos materiais e simbólicos (valores, crenças, regras sociais etc.)" (SOUZA et al., 2014, p.132).

A perspectiva sociocultural pode ser observada no Estatuto da Criança e do Adolescente na medida em que, como política pública, considera a condição peculiar de crianças e adolescentes como pessoas em desenvolvimento e destaca a importância do fortalecimento de vínculos familiares e comunitários, como os meios sociais nos quais crianças e adolescentes estão inseridos. Nessa perspectiva, Didonet (2015) afirma que o ECA volta sua atenção para a individualidade da criança e do adolescente, respeitando a diversidade. $O$ autor aponta que o Estatuto considera o 
contexto familiar, comunitário, étnico, religioso, social e cultural no qual crianças e adolescentes estão inseridos. O olhar individualizado, dentro de uma perspectiva sociocultural, também pode ser observado no texto do Sistema Nacional de Atendimento Socioeducativo (SINASE) ao trazer, em suas diretrizes pedagógicas, o respeito à singularidade do adolescente e ao considerar, como um de seus princípios, o fortalecimento dos vínculos familiares e comunitários durante o processo socioeducativo (BRASIL, 2012).

Além da adoção de uma visão sobre desenvolvimento humano pautada em aspectos socioculturais o ECA, em uma perspectiva normativa, utiliza uma visão cronológica. A referida lei considera como criança a pessoa de até 12 anos de idade incompletos e considera a adolescência como a faixa etária de 12 a 18 anos de idade. Em casos excepcionais, e quando disposto na lei, o estatuto é aplicável até os 21 anos de idade (BRASIL, 1990; EISENSTEIN, 2005).

Destaca-se que a relação entre idade cronológica e processo de desenvolvimento humano não é linear e natural, depende também de processos históricos e culturais. A diferenciação entre as fases demonstra o desafio de se estabelecer um limite etário, visto que na cultura ocidental não há uma demarcação clara para a transmissão de uma fase para outra, tal qual o rito de passagem para a vida adulta em outras culturas (OLIVEIRA et al., 2015).

Corroborando com essa afirmação, Sposito e Carrano (2003) consideram que quando se leva em conta somente a idade cronológica para a execução de políticas públicas é desconsiderado um conjunto de indivíduos que atinge a maioridade mas ainda vive em condição juvenil e, portanto, passível de ações pertinentes com sua condição de fato.

As fases da vida não são etapas rígidas, mas processos sócio-histórico-culturais que variam de acordo com as experiências dos sujeitos e conforme os contextos nos quais eles estão inseridos. Logo, o desenvolvimento humano pode seguir por diferentes percursos, de acordo com as experiências vividas e condições dadas pelo contexto social (SOUZA, 2016; OLIVEIRA et al., 2015).

\section{Vulnerabilidade social, fatores de risco e fatores de proteção}

Faz-se necessário melhor entender as definições de vulnerabilidade social e de risco social, visto que, como discorre Janczura (2012) há confusão no uso dessas definições. Ao se consultar no dicionário a definição de risco, observa-se que esse está relacionado à "possibilidade de perigo ou ameaça a pessoas ou ao ambiente" (DICIONÁRIO, 2019).

Yunes e Szymanski (2001, p. 4) discorrem que o termo 'de risco' foi utilizado por epidemiologistas em associação a grupos e populações e consideram que "fatores de risco relacionam-se com toda a sorte de eventos negativos de vida e que, quando presentes, aumentam a probabilidade de o indivíduo apresentar problemas físicos, sociais ou emocionais". Oliveira et al. (2015) apontam que, na sociedade ocidental, a noção de risco se expandiu dos fenômenos imponderáveis para se referir a grupos ou classes de pessoas, criando ligações até então inexistentes para o termo, como por exemplo a relação entre perigo e pobreza.

No Brasil, o senso comum associou comportamentos considerados moralmente errados pela sociedade às classes menos favorecidas, evidenciando aspectos como decadência moral, conduta infracional, mendicância e ameaça ao convívio social. Nesse cenário, a pobreza relacionava-se com generalizações indevidas tais como a criminalidade (COIMBRA, 2001, OLIVEIRA et al., 2015, SANTOS, 2004).

Autores como Rizzini e Rizzini (2004) preferem a utilização de termos como adversidade e/ou vulnerabilidade social em vez de 'risco', considerando que o termo 'de risco' é usualmente 
utilizado de forma equivocada para rotular a população de baixa renda, destacando jovens e negros, como iminentemente perigosos.

As afirmações de Rizzini e Rizzini (2004) vão ao encontro de Adorno (2002) que, ao relacionar criminalidade com pobreza, afirma que apesar da maior parte dos indivíduos envolvidos em crimes serem de origem de classes trabalhadoras paupérrimas, a maioria, pertencentes a essas classes e submetidos às mesmas condições de vida, não ingressam na criminalidade. Isso se justifica pelo fato de que o desenvolvimento do indivíduo ocorre por meio de relações dialéticas que flutuam entre determinação e "resistência às condições materiais e simbólicas de existência de cada sujeito, dadas as condições materiais e simbólicas de existência de cada um" (OLIVEIRA et al., 2018, p. 77).

Com uma visão mais determinista, Pereira et al. (2015) consideram que dificuldades financeiras e restrição, culminadas com a dificuldade de entrada no mercado de trabalho, podem oportunizar o ingresso de jovens em atividades ilícitas com o propósito de gerar renda, visto o peso do consumo como status da formação social da identidade juvenil.

Entretanto, as afirmações de Pereira et al. (2015) não podem ser vistas de forma generalizada dentro da perspectiva atual de desenvolvimento humano, posto que diante de dificuldades e impedimentos semelhantes, determinadas pessoas de determinados grupos podem estar mais vulneráveis aos tropeços, enquanto outros tendem a se fortalecer diante das adversidades (OLIVEIRA et al., 2015).

Por sua vez, Abramovay (2002) define vulnerabilidade social como sendo a situação pela qual um conjunto de recursos e habilidades de um determinado grupo social se revelam limitados, inadequados ou difíceis para enfrentar o sistema de chances oferecido pela sociedade. Nesse sentido Oliveira et al. (2015) argumentam que a vulnerabilidade social está relacionada à precariedade de condições de trabalho e emprego e à fragilidade da rede de suporte social dentro de uma determinada comunidade.

Apoiando-se nas contribuições de Yunes e Szymanski (2001), Adorno (2002), Rizzini e Rizzini (2004), Costa e Assis (2006) e Oliveira et al. (2015), considera-se que não existe uma relação de causa entre a vulnerabilidade social e o cometimento de crimes ou contravenções penais, mas sim uma reação dialética entre as situações de risco e proteção, dando origem à resiliência.

Considera-se situações de risco "os aspectos socioculturais e experimentais representados como negativos que contribuem para ampliar a vulnerabilidade de pessoas e grupos" (OLIVEIRA et al., 2015, p. 60). Entre as situações que representam risco para o adolescente estão o afastamento do convívio familiar, o envolvimento com grupos transgressores, o abandono escolar e consumo abusivo de álcool e drogas. Destaca-se que os fatores de risco não podem ser analisados de forma isolada e independente, mas sim a partir de uma perspectiva na qual estas questões estão inter-relacionadas, dentro de cada contexto individual (OLIVEIRA et al., 2015; DELLECAVE et al., 2018).

Em contrapartida, os fatores de proteção se relacionam à oferta de condições de crescimento e de desenvolvimento. Os fatores de proteção, tais como autoestima, relações pessoais positivas com companheiros, professores, familiares, vizinhança, além do apoio emocional e social recebidos por esses, representam um suporte que intervém nas situações de risco às quais o público jovem está potencialmente submetido, modificando a resposta do indivíduo aos processos de risco (AMPARO, 2008).

Diante do exposto, ao analisar fatores de risco e proteção, é importante ter em mente que a trajetória do adolescente expressa os processos de individualização e/ou socialização, nos quais a família, a religião, a escola e as organizações para as atividades de esporte, lazer e cultura 
possibilitam o desenvolvimento individual e geram ou reforçam as expectativas de realização pessoal (SIERRA, 2019).

Corroborando para o entendimento da importância dos fatores de proteção e reconhecendo o cumprimento de medida socioeducativa como um processo de mudança na vida do indivíduo, e possivelmente um evento estressor, o ECA elencou uma série de direitos que devem ser garantidos ao adolescente durante o cumprimento dessas medidas, entre estes: realizar atividades culturais, esportivas e de lazer; receber assistência religiosa; receber escolarização e profissionalização; permanecer internado na mesma localidade ou naquela mais próxima ao domicílio de seus pais ou responsável, entre outros.

E é diante do paradigma da garantia de direitos que as instituições socioeducativas, entre elas as de semiliberdade, devem proporcionar a construção de um ambiente favorável para o fortalecimento dos fatores de proteção por meio de uma sólida rede de atendimento.

\section{Metodologia}

Trata-se de um estudo de abordagem de natureza quantitativa, a partir do levantamento de dados secundários coletados nos registros eletrônicos das unidades de semiliberdade que estão registrados no Sistema de Informações para Infância e Adolescência (SIPIA), sobre o perfil de adolescentes em conflito com a lei, em cumprimento de semiliberdade no Distrito Federal. Tratase de uma base única de dados, hospedada em plataforma web, que permite que todos os órgãos envolvidos na atividade socioeducativa possam alimentar e acessar as informações disponíveis.

A realização da pesquisa e as visitas às unidades socioeducativas de semiliberdade para a coleta de dados foram precedidas por expressa autorização da Vara de Execução de Medidas Socioeducativas do DF e da Gerência de Estudos Socioeducativos da Secretaria de Justiça e Cidadania do Distrito Federal, mediante a entrega do projeto de pesquisa.

Para a captação foram realizadas visitas, no período entre junho e agosto de 2019, às seis unidades de atendimento socioeducativo do Distrito Federal: Guará, Gama, Santa Maria Taguatinga I, Recanto das Emas e Taguatinga II. Apesar de algumas das unidades utilizarem, além do SIPIA, outros mecanismos de registro para cadastrar e contabilizar o efetivo de socioeducandos, a escolha pelos dados registrados no SIPIA justifica-se por este conter campos padrões de preenchimento obrigatórios para todas as unidades.

Ressalta-se que os dados acessados dizem respeito somente àqueles que são registrados e atualizados pelas próprias unidades, sem acesso a nomes de adolescentes, planos de atendimento, textos de processos ou qualquer outro tipo de informação confidencial.

Neste trabalho são apresentadas a descrição e análise referentes às variáveis: idade, sexo, etnia, escolaridade, situação profissional, convívio familiar, bairro de residência, renda familiar e uso de drogas. Para a descrição das variáveis escolhidas, foi utilizado o programa Microsoft Excel. Para a verificação do teste de associação entre variáveis, foi utilizado o programa Statistical Package for Social Sciences (SPSS), versão 22. Para as variáveis categóricas foram utilizados os testes Qui-Quadrado e Exato de Fisher. Já se tratando da variável quantitativa idade foi utilizado o teste estatístico não paramétrico de Kruskal-Wallis, tendo em vista que tal variável não segue uma distribuição normal de probabilidade. Vale salientar que foi utilizado um nível de 5\% de significância nos resultados obtidos (o mesmo que 95\% de confiança).

\footnotetext{
${ }^{6}$ Apesar de se chamar Unidade de Semiliberdade de Santa Maria, essa localiza-se atualmente na Região Administrativa do Gama.
} 


\section{Resultados e discussão}

Apresenta-se, a seguir, a descrição e análise referentes às variáveis idade, sexo, etnia, escolaridade, situação profissional, convívio familiar, bairro de residência, renda familiar e uso de drogas.

\section{Adolescentes em semiliberdade no DF: sexo e idade}

As medidas socioeducativas são sanções destinadas a adolescentes entre 12 e 18 anos incompletos que cometeram ato infracional, isto é, crime ou contravenção penal. A Tabela 1 apresenta os dados referentes à distribuição por sexo e idade dos adolescentes que ingressaram em unidades de semiliberdade no Distrito Federal no ano de 2018.

Tabela 1 - Frequência absoluta de adolescentes em cumprimento de medida de semiliberdade no DF por sexo e idade -2018

\begin{tabular}{l|l|l|l|l}
\hline \multirow{2}{*}{ Idade } & \multicolumn{3}{|l|}{ Sexo Masculino } & Sexo Feminino \\
\cline { 2 - 5 } & Frequência & Total & Frequência & Total \\
\hline 13 & 3 & $0,51 \%$ & - & - \\
\hline 14 & 12 & $2,05 \%$ & 3 & $17,64 \%$ \\
\hline 15 & 52 & $8,88 \%$ & 3 & $17,64 \%$ \\
\hline 16 & 110 & $18,80 \%$ & 5 & $29,41 \%$ \\
\hline 17 & 219 & $37,43 \%$ & 2 & $11,76 \%$ \\
\hline 18 & 130 & $22,22 \%$ & - & - \\
\hline 19 & 41 & $7 \%$ & 3 & $17,64 \%$ \\
\hline 20 & 16 & $2,43 \%$ & 1 & $5.88 \%$ \\
\hline Total & 2 & $0,34 \%$ & - & - \\
\hline & $\mathbf{5 8 5}$ & $\mathbf{1 0 0 \%}$ & $\mathbf{1 7}$ & $\mathbf{1 0 0 \%}$ \\
\hline
\end{tabular}

Fonte: SIPIA/2018 - organizados pelos autores a partir do banco de dados das unidades.

No âmbito do Distrito Federal, o atendimento de adolescentes do sexo feminino em unidades de semiliberdade iniciou-se no ano de 2014, com a inauguração da Unidade de semiliberdade do Guará. Antes da existência da referida unidade, as adolescentes que cometiam ato infracional no DF somente poderiam ser sentenciadas às medidas socioeducativas de internação ou à medida socioeducativa de meio aberto.

A não existência de uma unidade de semiliberdade destinada ao público feminino violava os preceitos básicos do ECA quanto à aplicação do conjunto completo das medidas socioeducativas. $O$ estatuto considera que a escolha da medida socioeducativa aplicada ao adolescente, pela autoridade competente, mediante o cometimento do ato infracional, deve levar em conta a capacidade de cumpri-la, as condições de ocorrência do ato e a gravidade da infração.

Evidenciou-se que no cenário do DF a porcentagem de adolescentes do sexo feminino em cumprimento de medida socioeducativa no ano de 2018 foi de $2,82 \%$, valor esse inferior aos registrados no Levantamento Anual SINASE (BRASIL, 2017), que foi de $4 \%$ em 2016, e dos encontrados por Nardi et al. (2014) que detectaram em suas pesquisas que $6 \%$ dos adolescentes eram do sexo feminino em Porto Alegre (RS).

Nardi et al. (2014) relatam uma possível explicação para a discrepância existente entre o número de adolescentes do sexo masculino quando comparado ao número de adolescentes 
do sexo feminino em cumprimento de medida socioeducativa. Segundo as autoras as questões culturais, embasadas na desigualdade entre os sexos, buscam justificar determinados comportamentos e favorecem para um maior envolvimento de adolescentes no sexo masculino em comportamentos agressivos.

Embora na descrição realizada o número de adolescentes do sexo feminino ser significativamente menor quando comparado ao sexo masculino no DF, Oliveira et al. (2018) discorrem que houve um crescimento da infração juvenil feminina no Brasil e no mundo a partir de duas possíveis explicações - a primeira relaciona-se à tendência de punir a adolescente diante do cometimento do ato infracional; e o segundo em retirar um problema não-resolvido da zona de visibilidade social. Ainda sobre adolescentes do sexo feminino em cumprimento de medida socioeducativa, Araújo (2004) discorre que o poder de ação e de representação social das adolescentes, em um mundo preponderantemente masculino, agrega as chances dessas de exposição ao risco e à vulnerabilidade social e pessoal.

Analisando a distribuição das idades dos adolescentes no ano de 2018, nas unidades socioeducativas, foi percebido que os adolescentes, com idade mínima em cumprimento dessa medida, tinham 13 anos e idade máxima de 21 anos, respeitando a definição do ECA que considera adolescente como sendo a pessoa com idade entre 12 e 18 anos incompletos e respeitando a idade limite de vinte e um anos para a concessão de liberdade compulsória àqueles que estejam cumprindo as medidas socioeducativas.

As unidades destinadas ao atendimento do público masculino possuem divisão específica por faixa etária, tal qual preconiza o SINASE: os jovens de 18 a 21 anos são vinculados à Unidade de Taguatinga I; os adolescentes de 16 a 17 anos, maioria no sistema, são vinculados às Unidades do Recanto das Emas, Santa Maria e Gama: e os adolescentes de 12 a 15 anos são vinculados à Unidade de Taguatinga II. Essa divisão por faixa etária apareceu evidenciada na análise dos dados diante do registro de um desvio padrão da categoria idade entre as unidades masculinas menor, quando comparado ao desvio padrão apresentado pela categoria idade na unidade feminina, única para o atendimento de todas as faixas etárias.

Os dados levantados na medida de semiliberdade do DF, evidenciam que a maior parte do total de adolescentes, 58,30\%, encontra-se na faixa etária de 17 e 18 anos (36,71\% do total de adolescentes tinham 17 anos e $21,59 \%$ possuíam $18^{7}$ anos). Os resultados referentes à idade no DF, diferenciam-se de uma tendência apontada pelo Levantamento Anual SINASE (BRASIL, 2017), que constatou que $57 \%$ dos adolescentes presentes no sistema socioeducativo nacional estavam na faixa etária entre 16 e 17 anos; e os resultados encontrados por Zappe e Ramos (2010) que, ao realizar pesquisa no Centro de Atendimento Socioeducativo Regional de Santa Maria (RS), durante o período de 1998 a 2007, constataram que a maioria dos adolescentes inseridos no sistema socioeducativo local também possuíam entre 16 e 17 anos.

Sobre a questão etária, Zappe e Ramos (2010) discorrem que ao final da adolescência a necessidade de inclusão dos adolescentes, por meio do desejado consumo, aparece com maior intensidade levando os jovens a utilizarem recursos como o ato infracional para incluir-se em grupos de consumo. Na conjuntura atual, as experiências vividas pelos adolescentes recebem direta influência da cultura do consumo, intervindo em seus comportamentos e nos significados que eles desenvolvem na própria adolescência (SOUZA et al., 2014).

\footnotetext{
${ }^{7}$ Ressalta-se que o momento em que o adolescente ingressa na unidade de atendimento não necessariamente corresponde ao momento da prática do ato infracional, visto que há um trâmite legal até que ele seja sentenciado.
} 
Comparando os valores encontrados nas unidades de semiliberdade do DF para a variável idade entre 12 e 15 anos, aos valores encontrados por Fuchs (2009) no cenário nacional no ano de 2008, observa-se que o número de adolescentes no DF nessa faixa etária é de $12,5 \%$, enquanto os encontrados pela autora foram de $18 \%$.

Outro resultado observado foi a relação entre idade e situação escolar. A aplicação do teste estatístico não paramétrico de Kruskal-Wallis verificou a existência de associação estatisticamente significativa de p>0.000 entre as variáveis idade e situação escolar de modo que, em média, indivíduos com idades menores tendem a estar estudando atualmente.

\section{Adolescentes em semiliberdade no DF: região administrativa de origem}

O DF possui, atualmente, 33 Regiões Administrativas (RA). Estas são subdivisões territoriais com limites físicos determinados pelo poder público local. Observando dados referentes à frequência de adolescentes por região administrativa (Tabela 2), é possível constatar que a maioria dos adolescentes, 55,65\%, são oriundos de cinco RAs: Ceilândia, Samambaia, Planaltina, Recanto das Emas e São Sebastião. Dentre essas RAs, somente a RA Recanto das Emas possui unidade de semiliberdade instalada.

Tabela 2 - Frequência absoluta de adolescentes em cumprimento de medida de semiliberdade no DF segundo a Região Administrativa (RA) - 2018

\begin{tabular}{l|l|l}
\hline Região Administrativa & Frequência & Porcentagem \\
\hline Ceilândia & 116 & $19,27 \%$ \\
\hline Samambaia & 80 & $13,29 \%$ \\
\hline Planaltina & 58 & $9,63 \%$ \\
\hline Recanto das Emas & 44 & $7,31 \%$ \\
\hline São Sebastião & 37 & $6,15 \%$ \\
\hline Santa Maria & 30 & $4,98 \%$ \\
\hline Taguatinga & 29 & $4,82 \%$ \\
\hline Gama & 12 & $1,88 \%$ \\
\hline Guará & 8 & $1,33 \%$ \\
\hline Demais RAs DF & 188 & $31,34 \%$ \\
\hline Total & $\mathbf{6 0 1}$ & $\mathbf{1 0 0}$ \\
\hline
\end{tabular}

Fonte: SIPIA/2018 - organizados pelos autores a partir do banco de dados das unidades.

A RA Taguatinga, região na qual estão instaladas duas unidades de semiliberdade, possui somente $4,82 \%$ de adolescentes em cumprimento de medida socioeducativa de semiliberdade residentes da região. Em contrapartida, Ceilândia, RA que possui mais de 19,27\% dos adolescentes em regime de semiliberdade, não dispõe de unidade de semiliberdade, sendo os adolescentes residentes nessa RA, alocados nas seis unidades de semiliberdades disponíveis no Distrito Federal.

Em situação semelhante à RA Taguatinga está a RA do Gama, que possui 1,86\% dos adolescentes em cumprimento de medida de semiliberdade. Por sua vez Planaltina, local de residência de 9,63\% dos adolescentes inseridos no regime de semiliberdade, não possuiu unidade de

\footnotetext{
${ }^{8}$ Plano Piloto, Taguatinga, Brazlândia, Sobradinho, Paranoá, Núcleo Bandeirante, Cruzeiro, Lago Sul, Riacho Fundo, Lago Norte, Candangolândia, Águas Claras, Riacho Fundo II, Sudoeste/Octogonal, Varjão, Park Way, SCIA, Jardim Botânico, Itapoã, SIA, Vicente Pires, Fercal, Sol Nascente e Arniqueira.
} 
semiliberdade instalada e a unidade de semiliberdade mais próxima à RA Planaltina se encontra a mais de $53 \mathrm{~km}$ de distância.

O levantamento ainda apontou que, devido ao critério de divisão etária adotado pelas unidades masculinas, nem sempre os adolescentes domiciliados nas RAs, onde estão instaladas unidades de semiliberdade, cumprem suas sentenças no local de domicílio. Um exemplo nítido desse fenômeno é observado na Unidade de semiliberdade do Recanto das Emas. Dos adolescentes vinculados à unidade no ano de 2018 , somente $11,58 \%$ possuíam domicílio na mesma RA. 0 mesmo pode ser observado nas outras quatro unidades masculinas de semiliberdade. A unidade de Taguatinga I possui 4,65\% de adolescentes residentes na RA, enquanto Taguatinga II, Gama e Santa Maria apresentam 4,03\%, 3,43\% e 2,46\% respectivamente.

Como causa para esse fenômeno, além da condição etária, outro fator chama atenção e explica esse dado, as "guerras" na comunidade. As "guerras", assim chamadas pelos adolescentes, são conflitos de rivalidade entre adolescentes de um mesmo bairro, com grupos de adolescentes de bairros ou quadras vizinhas dentro de uma mesma RA.

Segundo Souza et al. (2014) devido a rivalidades e brigas entre grupos, determinados adolescentes são impelidos de circular em alguns territórios. Nesses casos, os gestores das unidades de semiliberdade e as equipes técnicas de atendimento optam por separar adolescentes de grupos rivais em diferentes unidades para que não ocorram casos de violência entre os jovens. A rivalidade entre os adolescentes é detectada no ingresso do jovem na unidade, durante $o$ atendimento inicial.

Observa-se, ao analisar o percentual de adolescentes femininas por RA, vinculadas à unidade de semiliberdade do Guará no ano de 2018, que nenhuma das socioeducandas possuía residência na RA Guará, sendo a maior parte dessas pertencentes aos bairros de Ceilândia (25\%), Sobradinho (18,75\%), Samambaia (12,5\%) e Planaltina (12,5\%). Destaca-se que a unidade é a única para atendimento de semiliberdade para adolescentes do sexo feminino.

A constatação de distanciamento entre local de instalação das unidades e a Região Administrativa de origem do adolescente, pode ser percebido como um fator de vulnerabilidade social que vai de encontro às perspectivas apresentadas pelo ECA.

o cumprimento de medida socioeducativa em unidade de atendimento mais próxima ao domicílio de seus pais ou responsáveis está descrito no inciso VI, do artigo 124 do ECA. Além disso, o SINASE, em seus princípios, destaca que as medidas socioeducativas devem ser regidas pelo princípio do fortalecimento dos vínculos familiares e comunitários, entre outros. Logo, considera-se que a convivência familiar e comunitária é de grande importância para o processo do desenvolvimento humano. Na maioria dos casos, família e comunidade figuram como fatores de proteção por representarem um suporte que intervém nas situações, modificando a resposta do indivíduo aos processos de risco em que possa estar inserido (AMPARO, 2008).

Souza et al. (2014) esclarecem que essa vulnerabilidade prejudica a efetivação de planos para o futuro, aumentando a desproteção social que marca o desenvolvimento do indivíduo enquanto adolescente. Sierra e Mesquita (2006) ainda destacam que a qualidade da infância e da adolescência depende da relação do indivíduo com a família e é marcada pelo lugar de moradia, pela comunidade e pelos serviços públicos ali ofertados.

Os dados referentes ao local de residência dos adolescentes apontam para a necessidade de construção de novos centros de atendimento em regiões como Ceilândia, Samambaia e Planaltina, com o objetivo de que a medida socioeducativa possa fortalecer os vínculos entre o adolescente, sua família e sua comunidade de origem. Além disso, destaca-se a importância de implementação 
de políticas públicas que se convertam em fatores de proteção, tais como a instalação de locais que garantam a prática de esportes, ao acesso à produção cultural, oportunidades de orientações profissionais e escolares.

\section{Adolescentes em semiliberdade no DF: perfil étnico-racial}

A população negra no Brasil encontra-se submetida às piores condições de saúde, educação, renda, acesso a empregos estáveis, violência ou expectativa de vida (JACCOUD, 2008). Em relação ao ingresso no sistema socioeducativo, os dados corroboram com esse argumento (Tabela 3).

Tabela 3 - Frequência absoluta de adolescentes em cumprimento de medida de semiliberdade no DF segundo a etnia - 2018

\begin{tabular}{l|l|l}
\hline Etnia & Frequência & Porcentagem \\
\hline Amarela & 1 & $0,17 \%$ \\
\hline Branca & 38 & $6,32 \%$ \\
\hline Índia & 4 & $0,67 \%$ \\
\hline Não Informada & 91 & $15,14 \%$ \\
\hline Negra & 84 & $13,98 \%$ \\
\hline Parda & 383 & $63,73 \%$ \\
\hline Total Geral & $\mathbf{6 0 1}$ & $\mathbf{1 0 0 , 0 0 \%}$ \\
\hline
\end{tabular}

Fonte: SIPIA/2018 - organizados pelos autores a partir do banco de dados das unidades.

O percentual de adolescentes afrodescendentes (negros ou pardos) equivale a 77,71\% do total de adolescentes em semiliberdade no DF. Melo (2001) considera que a origem do grande número de adolescentes negros e pardos nos efetivos das Unidades de Atendimento Socioeducativo está relacionada ao curso histórico de exclusão social ao qual esse grupo está submetido e pelo fato de que, provavelmente, o adolescente da etnia negra e parda, independentemente de estar ou não mais envolvido com a prática de atos infracionais, na maioria dos casos é mais encaminhado às delegacias e ao poder judiciário que o adolescente branco. Levantamento realizado pelo IPEA (2011) apontou que a população que se autodenomina afrodescendente (negros ou pardos) é maioria no Brasil, e é predominantemente jovem, possui o número maior de filhos e está mais exposta a maiores taxas de mortalidade por violência quando comparada à população branca.

Resultados similares foram encontrados por Fuchs (2009) com relação aos adolescentes em semiliberdade no cenário nacional. A autora discorre que a figura do negro na história brasileira aparece constantemente relacionada ao fenômeno da desigualdade social do país.

Quando os resultados encontrados são comparados à realidade da população do DF em faixa etária similar, observam-se valores um pouco superiores aos apresentados pelo Perfil da Juventude do Distrito Federal (levantamento realizado pela CODEPLAN, 2018). Segundo esse levantamento, a população de jovens do DF entre 15 e 17 anos é formada por 63\% de afrodescendentes. A desigualdade étnico-racial dentro do sistema socioeducativo traduz a permanência de uma cultura de discriminação, conforme é apontado por Rizzini e Rizzini (2004) e Silva (1997).

\section{Adolescentes em semiliberdade no DF: situação escolar e situação profissional}

Analisando os dados coletados, foi possível constatar que $60,39 \%$ dos adolescentes estavam estudando, enquanto $27,62 \%$ não estavam inseridos no ambiente escolar, e 10,98\% estavam 
matriculados, mas não frequentavam as aulas. O distanciamento do adolescente do ambiente escolar é amplamente sinalizado por diversos autores como um traço negativo marcante da trajetória de vida de adolescentes que então se envolvem em atos delituosos (CRUZ, 2010; FUCHS, 2009; GALLO, 2006, CUNHA; DAZZANI, 2018).

Somado a isso, Cunha e Dazzani (2018) apontam que o adolescente fora da escola encontra-se mais vulnerável à adesão de práticas de ato infracional. Os autores ainda consideram que a frequência escolar e o envolvimento no ambiente escolar funcionam como fatores de proteção para o afastamento da conduta infracional.

Outro fator de relevância sobre a relação entre frequência escolar e adolescente em cumprimento de medida socioeducativa foi elencado por Ferreira (2015) em pesquisa realizada com vinte adolescentes em cumprimento de medidas socioeducativas no Norte do Paraná. A autora evidenciou, através da fala dos entrevistados, que a escola se constitui em uma possibilidade de humanização pouco efetivada e concretizada na visão dos adolescentes. Zappe e Ramos (2010), em perspectiva similar, apontaram que a educação para os adolescentes em conflito com a lei parece não se mostrar um veículo efetivo de inserção social.

Ao confrontar a variável sexo com a variável situação escolar, observou-se a existência de associações estatisticamente significativas, de modo que o indivíduo do sexo masculino tem uma chance maior de não estudar atualmente do que o indivíduo do sexo feminino (dos que não estudam atualmente 99,3\% são do sexo masculino e 0,7\% do sexo feminino).

Quanto à escolaridade dos adolescentes em semiliberdade do DF (Tabela 4), foi verificado que a maior parte dos adolescentes, 89\%, ainda está no Ensino Fundamental, apesar de a maioria já ter idade de tê-lo concluído visto que a maior parte dos adolescentes presentes nas unidades de semiliberdade possuía 17 e 18 anos. Zappe e Ramos (2010) e Fuchs (2009) também chegaram a resultados similares em seus levantamentos, observando grande defasagem idade/série escolar entre os adolescentes que cumpriram medida socioeducativa de internação em RS e de semiliberdade no Brasil.

Tabela 4 - Frequência absoluta de adolescentes em cumprimento de medida de semiliberdade no DF segundo a escolaridade - 2018

\begin{tabular}{l|l|l}
\hline Escolaridade & Frequência & Porcentagem \\
\hline Não Alfabetizado & 2 & $0,33 \%$ \\
\hline Alfabetizado & 12 & $2,00 \%$ \\
\hline Ensino Fundamental Incompleto & 479 & $79,56 \%$ \\
\hline Ensino Fundamental Completo & 56 & $9,30 \%$ \\
\hline Ensino Médio Incompleto & 45 & $7,47 \%$ \\
\hline Ensino Médio Completo & 2 & $0.33 \%$ \\
\hline Não informado & 6 & $0,99 \%$ \\
\hline Total & $\mathbf{6 0 2}$ & $\mathbf{1 0 0 \%}$ \\
\hline
\end{tabular}

Fonte: SIPIA/2018 - organizados pelos autores a partir do banco de dados das unidades.

Fuchs (2009, p.122) afirma que a questão da escolaridade defasada e da evasão escolar, evidenciada também em sua pesquisa de âmbito nacional, quando associada a outras vulnerabilidades "pode ser um indicador de aproximação com o mundo da marginalidade e da prática infracional". 
Um dos possíveis motivos para essa defasagem na relação idade e série pode ser motivado pela postura da escola diante dos diferentes grupos de adolescentes, "que tende a generalizar, homogeneizar os sujeitos, não se preocupando com as diferenças, afastando da escolarização os jovens que apresentam dificuldades, mantendo um círculo contínuo de exclusão" (PADOVANI; RISTUM, 2013, p. 9).

Quando é analisado o perfil dos adolescentes quanto à situação profissional desses, observa-se que 53,72\% não trabalhavam no momento, ou nunca haviam trabalhado. Contrapondo a esse dado, dos 205 adolescentes (34,11\%) que exerciam alguma atividade remunerada, somente 22 adolescentes, equivalente a 3,63\%, trabalhavam com carteira assinada.

Sobre a ocupação dos adolescentes em conflito com a lei, Assis e Constantino (2005) salientam que o mercado de trabalho para os jovens, sejam eles inseridos em um contexto de infração, ou não, é bastante restrito, em especial para adolescentes com baixa escolaridade. As autoras ainda endossam que diante da ausência de boas opções no mercado de trabalho, muitos jovens se inserem em atividades ilícitas.

Sob o mesmo ponto de vista, Castro e Abramovay (2002) apontam que os jovens são atingidos pelas maiores taxas de desemprego e de subemprego no Brasil, e mesmo aqueles que possuem algum trabalho estão envolvidos em atividades informais, sem vínculo empregatício. As autoras também destacam que ao evadir-se do ambiente escolar o jovem tem suas chances de inserção no mercado de trabalho reduzidas, já que não dispõe das credenciais escolares exigidas nos postos de emprego.

A falta de escolaridade, aliada ao não acesso ao mercado de trabalho dão origem a outra questão, a frustração do desejo de consumo. Cunha e Dazzani (2018) descrevem que a escolarização é percebida como condição indispensável para conseguir emprego. Acrescentam, ainda, que o ingresso no mercado de trabalho proporciona certa independência financeira, portanto relativo acesso aos bens de consumo, inclusão e ascensão social.

Ao analisar a correlação entre as variáveis situação escolar e situação profissional é observado que essas possuem associação estatisticamente significativa, com nível de significância de 0.000 , de modo que quem está estudando tende a não trabalhar atualmente (percentual de $32,1 \%$ dos que não trabalham). Corroborando com o resultado encontrado, Assis (2001), em sua pesquisa com adolescentes em conflito com a lei, descreveu que entre os fatores de abandono escolar estavam a necessidade de trabalhar e a dificuldade em conciliar escola e trabalho.

\section{Adolescentes em semiliberdade no DF: convívio familiar ${ }^{9}$}

A instituição familiar constitui um importante elemento para o processo de desenvolvimento humano. É no ambiente familiar onde se formam as primeiras relações sociais do indivíduo. A Tabela 5 apresenta a frequência absoluta de adolescentes em cumprimento de medida de semiliberdade no DF segundo o convívio familiar.

Tabela 5 - Frequência absoluta de adolescentes em cumprimento de medida de semiliberdade no DF segundo o convívio familiar - 2018

\begin{tabular}{l|l|l}
\hline Convívio Familiar & Frequência & Porcentagem \\
\hline Em situação de rua & 1 & $0,17 \%$ \\
\hline
\end{tabular}

${ }^{9}$ Os dados nomeados como convívio familiar no banco de dados pesquisado se limitam à composição de co-habitação, e não às relações qualitativas que caracterizam o convívio. 


\begin{tabular}{l|l|l}
\hline Companheira(o) & 28 & $5,16 \%$ \\
\hline Mora sozinho & 3 & 0,5 \\
\hline Mora com pai e mãe & 103 & $17,14 \%$ \\
\hline Mora com o pai & 36 & $5,99 \%$ \\
\hline Mora com a mãe & 347 & $57,74 \%$ \\
\hline Outros $^{10}$ & 83 & $13,81 \%$ \\
\hline Total & $\mathbf{6 0 1}$ & $\mathbf{1 0 0 , 0 0 \%}$ \\
\hline
\end{tabular}

Fonte: SIPIA/2018 - organizados pelos autores a partir do banco de dados das unidades.

A análise da composição familiar dos adolescentes permite verificar a existência de um cenário plural de arranjos familiares diferentes da família nuclear tradicional, composta por um casal e filhos. Quando observados os percentuais de membros da família que viviam junto com o adolescente percebe-se que mais da metade morava só com a mãe, $57,74 \%$, enquanto $17,14 \%$ moravam com pai e mãe. Valores similares foram encontrados em outras pesquisas que buscaram traçar o perfil do adolescente em cumprimento de medida socioeducativa, apontando a monoparentalidade como um aspecto presente na maioria das famílias de jovens em conflito com a lei (NARDI et al., 2014; GALLO; WILLIAMS, 2005; DIAS et al., 2011).

Sobre a relação entre desigualdades sociais e vulnerabilidade social, Oliveira et al. (2015, p. 47) discorrem que diante de um cenário de exclusão de acesso a bens socioeconômicos e culturais essenciais "a família se torna fragilizada para cumprir, até mesmo, a parte essencial que lhe toca na formação de vínculos, da identidade, e na proteção dos filhos".

Utilizaram-se o teste do Qui-quadrado e Exato de Fisher para testar a associação entre variáveis. Constatou-se que as variáveis convívio familiar e situação escolar ${ }^{11}$ não possuem associação estatisticamente significativa no cenário pesquisado. Por sua vez, as variáveis convívio familiar e uso de droga ${ }^{12}$ demonstraram ter associação estatisticamente significativa. Destacase que associação estatística não é inferência de casualidade, já que diversos outros fatores de proteção, eventos estressores e situações de risco associados podem interferir na realidade dos indivíduos e em suas relações com a escola e o uso de drogas.

A pesquisa de Gallo (2006) descreveu que famílias monoparentais são influenciadas por inúmeros fatores de risco, considerando que a mulher, na maioria das vezes, para chefiar tais famílias lida com o estresse financeiro para custear os gastos domésticos e para educar os filhos. Confrontando o pensamento apresentado destaca-se que diante da perspectiva sociocultural, as famílias podem apresentar dinâmicas protetoras e educadoras, independentemente da situação econômica familiar ou da composição de seus membros. Mas não se pode atribuir unicamente à família do adolescente a responsabilidade de toda sua formação como sujeito, visto que esta não se dá em contexto isolado das condições sociais, materiais e históricas nas quais se encontram (PEDROZA, 2016).

Nardi et al. (2014) destacam a existência de uma discussão na literatura sobre a influência da ausência do pai constituir-se um fator negativo, outros apontam para uma ausência de influência. Apesar da existência das hipóteses de que a ausência materna ou paterna impacta na capacidade

\footnotetext{
${ }^{10}$ Mora com o(s) irmão(s); mora com outros familiares; mora com responsáveis; mora com amigos; mora em instituição governamental; mora em instituição não governamental.

${ }^{11}$ Nível de significância de 0.627 para as variáveis convívio familiar e situação escolar.

${ }^{12}$ Nível de significância de 0.001 para análise de relação entre as variáveis convívio familiar e uso de droga.
} 
de aprendizagem do indivíduo, ou ainda na ausência de limites e regras, a composição familiar não pode ser definida como um fator de vulnerabilidade (BISINOTO, 2014).

Destaca-se, ainda, que no contexto do Distrito Federal somente foi encontrado um caso de adolescente em situação de rua. Resultados similares foram informados por Assis e Costantino (2005) e por Fuchs (2009). Essa informação desmistifica o senso comum de que grande parcela dos adolescentes em conflito é composta por 'meninos em situação rua' (ASSIS; CONSTANTINO, 2005).

\section{Adolescentes em semiliberdade no DF: uso de drogas}

O uso de drogas pode resultar em dependência física, psicológica e emocional, podendo também colaborar para a prática de atos transgressivos e infrações, em especial por despertar no adolescente uma sensação de coragem e de inconsequência (SOUZA et al., 2014). A utilização precoce de drogas aumenta a vulnerabilidade e o indivíduo passa a desenvolver dependência dessas, sejam lícitas ou ilícitas (Tabela 6).

Tabela 6 - Frequência absoluta de adolescentes em cumprimento de medida de semiliberdade no DF segundo o uso de drogas - 2018

\begin{tabular}{l|l|l}
\hline Uso de drogas & Frequência & Porcentagem \\
\hline Utiliza & 362 & $60,23 \%$ \\
\hline Não utiliza & 218 & $36,27 \%$ \\
\hline Não informado & 21 & $3,49 \%$ \\
\hline Total & $\mathbf{6 0 1}$ & $\mathbf{1 0 0 , 0 0 \%}$ \\
\hline
\end{tabular}

Fonte: SIPIA/2018 - organizados pelos autores a partir do banco de dados das unidades.

Os dados analisados não trazem distinção sobre os diferentes tipos de drogas utilizadas, nem se lícitas ou ilícitas, somente apresenta dados sobre a utilização ou não dessas substâncias (Tabela 6).

A associação entre as variáveis idade e uso de drogas, realizada pelo teste estatístico não paramétrico de Kruskal-Wallis, apresentou o p-valor igual a 0,869 > 0,05. Sendo assim, foi observado que não há associação estatisticamente significativa entre as variáveis idade e drogas na amostra, não apontando correlação entre o uso de drogas e a idade do indivíduo.

O cruzamento entre a variável renda familiar e a variável uso de drogas, por meio do teste Qui-Quadrado e Exato de Fisher, apresentou nível de significância de 0.628 > 0,05, demonstrando que não há associação estatística significativa entre o consumo de drogas e a renda familiar dos adolescentes.

Pesquisa realizada por Lopes (2012) sobre o adolescente em cumprimento de medida socioeducativa no Estado do Paraná, diagnosticou que: 50\% do grupo de adolescentes com idade de 13 anos; $57 \%$ do grupo de adolescentes com idade de 16 anos; e 35,4\% dos adolescentes pertencentes ao grupo de 17 anos - declaravam fazer uso de drogas. Comparando com os dados encontrados por Lopes (2012) no cenário do Distrito Federal, o grupo que mais declarou fazer uso de drogas estava na faixa etária entre 16 e 18 anos, 48\% dos adolescentes com 16 anos declararam fazer uso de drogas, 64,25\% dos adolescentes com 17 anos e 72,30\% do grupo de adolescentes de 18 anos declararam fazer uso de drogas. 
A predominância de adolescentes em conflito com a lei que utilizam drogas também foi destacada por Fuchs (2009). A autora constatou que 94\% dos adolescentes em cumprimento de semiliberdade na região Centro-Oeste eram usuários de drogas.

\section{Adolescentes em semiliberdade no DF: renda familiar}

A desigualdade social no país reproduz-se nos resultados encontrados na análise quanto à renda familiar dos adolescentes em cumprimento de semiliberdade (Tabela 7). Os dados demonstram que mais da metade dos adolescentes, 51,75\%, vêm de família com renda familiar entre um e dois salários mínimos. Os dados encontrados na pesquisa são superiores aos apresentados pela Pesquisa Nacional por Amostra de Domicílios Contínua realizada pelo Instituto Brasileiro de Geografia e Estatística (IBGE) que constatou que 23,9\% das famílias brasileiras viviam com um orçamento mensal de até dois salários mínimos.

Tabela 7 - Frequência absoluta de adolescentes em cumprimento de medida de semiliberdade no DF segundo a renda familiar em salários mínimos - 2018

\begin{tabular}{l|l|l}
\hline Renda familiar & Frequência & Porcentagem \\
\hline Entre 01 e 02 SM & 311 & $51,75 \%$ \\
\hline Entre 02 e 03 SM & 117 & $19,47 \%$ \\
\hline Entre 03 e 05 SM & 57 & $9,48 \%$ \\
\hline Entre 05 e 07 SM & 13 & $2,16 \%$ \\
\hline Entre 07 e 10 SM & 2 & $0,33 \%$ \\
\hline Entre 10 e 15 SM & 2 & $0,33 \%$ \\
\hline Entre 15 e 20 SM & 2 & $0,33 \%$ \\
\hline Menos de 01 SM & 46 & $7,65 \%$ \\
\hline Não Informada & 51 & $8,48 \%$ \\
\hline Total Geral & $\mathbf{6 0 1}$ & $\mathbf{1 0 0 , 0 \%}$ \\
\hline
\end{tabular}

Fonte: SIPIA/2018 - organizados pelos autores a partir do banco de dados das unidades.

Com relação à correlação entre as variáveis renda e escolaridade, foi encontrada associação estatisticamente significativa de 0.021. De modo que os adolescentes com os níveis de escolaridade mais elevados também possuíam as maiores rendas familiares. 0 resultado aqui apontado leva a uma discussão que perpassa o senso comum de que pobre e pobreza são responsabilizados pela conjuntura de problemas escolares e por sua ineficiência (LEONARDO et al. 2012). Entretanto, diante de uma perspectiva sociocultural, diversos fatores externos tendem a contribuir como fator de risco ou de proteção dentro do ambiente de aprendizagem escolar, não podendo a baixa renda ser considerada causa do baixo rendimento escolar, embora seja fator relevante.

Apesar de Gallo (2006) considerar que as famílias monoparentais vivenciam um forte estresse financeiro para lidar com os filhos, o confronto entre renda familiar e convívio familiar apresentou um nível de significância de p-valor $0.349>0,05$, demonstrando a não existência de associação estatisticamente significativa entre as variáveis no contexto dos adolescentes em comprimento de semiliberdade no DF. 


\section{Considerações finais}

As análises e informações obtidas a partir desta pesquisa revelam que os adolescentes em cumprimento de medida de semiliberdade no DF são, em sua maioria, afrodescendentes (negros ou pardos) e que se encontram estudando (matriculados em instituição de ensino). Entretanto, possuem distorção na relação idade/série escolar; a maioria não trabalha e, quando inseridos em práticas laborais, não possuem carteira assinada e recebem baixa remuneração; são oriundos de famílias chefiadas só por mães e com renda familiar baixa; e residem em sua maioria, em três regiões administrativas do DF, Planaltina, Ceilândia e Sobradinho.

Em suma, os resultados encontrados, referentes à análise descritiva, são consonantes ao que apontam as pesquisas sobre desigualdade social no Brasil e os perfis de adolescentes em conflito com a lei apresentados por Gallo (2006), Zappe e Ramos (2010), Nardi et al. (2014) sobre as diferentes medidas socioeducativas. Quando os resultados encontrados são comparados aos levantados na pesquisa realizada por Fuchs (2009) sobre o perfil do adolescente em cumprimento de semiliberdade no Brasil, passados dez anos, percebe-se que o perfil do jovem em semiliberdade, pelo menos no DF, não é distinto e retratam um recorte classista e racista na aplicação da medida socioeducativa.

Considerando o âmbito do DF a pesquisa apontou que as variáveis convívio familiar e uso de droga possuem associação estatisticamente significativa. Tal associação não pode ser apontada como uma relação de causalidade, visto que a composição familiar, de forma isolada, não pode ser definida como um fator de vulnerabilidade. É possível verificar, ainda, ausência de associação estatística significativa entre as variáveis como uso de drogas e renda familiar dos adolescentes; idade e uso de drogas e convívio familiar e situação escolar, no contexto da população aqui analisada.

O resultado da pesquisa forneceu um panorama geral do perfil do adolescente em cumprimento de medida socioeducativa de semiliberdade no Distrito Federal. Observa-se que a parcela da população, aqui representada pelo perfil dos adolescentes em cumprimento de semiliberdade, vem sendo vítima de ausência de políticas públicas que fomentem a escolarização e a geração de renda, fatores esses que podem sugerir que esse grupo seja um possível alvo de um Estado que elege determinados segmentos da população para exercer seu poder coercitivo e repressor.

Os dados apontam para a necessidade de fomentar ações de políticas públicas com vistas à garantia de direitos e redução de fatores de risco, acesso e manutenção do ambiente escolar, prevenção ao uso de drogas, com maior intensidade em localidades específicas. Também carece de instalação de unidades de medidas de semiliberdade em outras regiões administrativas do $\mathrm{DF}$, onde hoje inexistem.

De verdade, muitas outras problemáticas ainda precisam de investigações mais aprofundadas, tanto abordagens quantitativas ou qualitativas, com uso de dados secundários disponíveis, quanto com a coleta de dados primários.

Apesar da pesquisa ter analisado somente o perfil do adolescente em cumprimento de medida socioeducativa de semiliberdade, é sabido que uma grande parcela dos adolescentes do Distrito Federal também se encontra em contextos similares de vulnerabilidade social e, diante da mesma situação. Porém, não são acometidos pela prática infracional, por várias razões, que aqui não são tratadas, por não serem o foco desta pesquisa. Com base nos resultados encontrados, a partir do perfil e das correlações realizadas, destaca-se a necessidade de uma pesquisa posterior, 
mais ampla, na qual os jovens em situação de vulnerabilidade no DF, com ou sem cometimento de ato infracional, possam ser ouvidos e suas colocações analisadas.

Enquanto o cenário aqui traçado não for alterado por políticas públicas efetivas, continua-se obtendo os mesmos dados em pesquisas, passados outros dez ou vinte anos, sem alcançar uma redução no número de adolescentes em conflito com a lei e, tampouco, uma melhoria na condição de vida desses indivíduos e de suas famílias.

\section{Referências}

ABRAMOVAY, Miriam; CASTRO, Mary Garcia; PINHEIRO, Leonardo de Castro; LIMA, Fabiano de Sousa; MARTINELLI, Cláudia da Costa. Juventude, violência e vulnerabilidade social na América Latina: desafios para políticas públicas. Brasília, UNESCO, 2002. Disponível em: http://www.alapop.org/alap/ images/PDF/ALAP2004_295.pdf. Acesso em: 02 fev. 2020.

ADORNO, Sérgio. Exclusão socioeconômica e violência urbana. Sociologias, Porto Alegre, v. 4, n. 8, p. 84-135, 2002. Disponível em: http://www.scielo.br/pdf/soc/n8/n8a05. Acesso em: 15 jan. 2020.

AMPARO, Deise Matos do; GALVÃo, Afonso Celso Tanus; ALVES, Paola Biasoli; BRASIL, Katia Tarouquella; KOLLER, Silvia Helena. Adolescentes e jovens em situação de risco psicossocial: redes de apoio social e fatores pessoais de proteção. Estud. psicol. (Natal), Natal, v. 13, n. 2, p. 165-174, ago. 2008. Disponível em: http://www.scielo.br/scielo.php?script=sci_arttext\&pid=S1413-294X20080002000 09\&lng=en\&nrm=iso. Acesso em: 11 fev. 2020.

ANDI, Comunicação e Direitos. Quais são os termos mais apropriados para se referir a crianças e adolescentes, quando se tem em vista a preservação de seus direitos?. [s.d.]. Disponível em: http://www.andi.org.br/help-desk/quais-sao-os-termos-mais-apropriados-para-se-referir-criancas-eadolescentes-quando-se-tem. Acesso em: 28 jul. 2020.

ARAÚJO, Domingos. O perfil das adolescentes que cometeram atos infracionais em Salvador no ano 2000. 2004. 129 f. Dissertação (Mestrado em Psicologia) - Universidade Federal da Bahia, Salvador, BA, 2004. Disponível em: https://ips.ufba.br/sites/ips.ufba.br/files/domingos_araujo.pdf. Acesso em: 23 jan. 2020.

ARAÚJO, Cláudio Márcio de; OLIVEIRA, Maria Cláudia Santos Lopes de. Significações sobre desenvolvimento humano e adolescência em um projeto socioeducativo. Educação em Revista, v. 26, n. 3, p. 169-194, 2010.Disponível em: http://www.scielo.br/scielo.php?script=sci_arttext\&pid $=$ S0102-46982010000300009. Acesso em: 20 dez. 2020.

ASSIS, Simone Gonçalves de. Filhas do mundo: infração juvenil feminina no Rio de Janeiro. Rio de Janeiro: Fiocruz, 2001.

ASSIS, Simone Gonçalves de; CONSTANTINO, Patrícia. Perspectivas de prevenção da infração juvenil masculina. Ciênc. saúde coletiva, Rio de Janeiro, v. 10, n. 1, p. 81-90, mar. 2005. Disponível em http:// www.scielo.br/scielo.php?script=sci_arttext\&pid=\$141381232005000100014\&lng=en\&nrm=iso. Acesso em: 31 mar. 2020.

BISINOTO, Cynthia. Repercussões das concepções de desenvolvimento no espaço educativo e na ação docente. In: BISINOTO, Cynthia. (Org.). Docência na Socioeducação. Brasília: Faculdade UnB Planaltina; Universidade de Brasília, 2014, p. 97-114. Disponível em: https:// docenciasocioeducacaounb.wordpress.com/sobre/material-livros/. Acesso em: 10 jan. 2020. 
BRASIL. Lei Federal no 8.069 de 13 de julho de 1990. Dispõe sobre o Estatuto da Criança e do Adolescente e dá outras providências. Brasília: Presidência da República; Casa Civil; Subchefia para Assuntos Jurídicos, 1990.

BRASIL. Lei Federal no 12.594 de 18 de janeiro de 2012. Institui o Sistema Nacional de Atendimento Socioeducativo (SINASE). Brasília: Presidência da República; Casa Civil; Subchefia para Assuntos Jurídicos, 2012.

BRASIL. Levantamento anual do SINASE 2017. Disponível em: https://prioridadeabsoluta.org.br/ wpcontent/uploads/2016/05/levantamentoanualdosinase2017.pdf. Acesso em: 19 de fev. 2020.

BRASIL. Pesquisa de Orçamentos Familiares 2019. Instituto Brasileiro de Geografia e Estatística (IBGE). Disponível em: https://biblioteca.ibge.gov.br/visualizacao/livros/liv101670.pdf. Acesso em: 22 de fev.2020.

CASTRO, Mary Garcia; ABRAMOVAY, M. Jovens em situação de pobreza, vulnerabilidades sociais e violências. Cad. Pesq., n.116, p.143-176, 2002. Disponível em: http://www.scielo.br/scielo. php?script=sci_arttext\&pid=S0100-15742002000200007. Acesso em: 15 jan. 2020.

COSTA, Antônio Carlos. Sócio-educação: estrutura e funcionamento da comunidade educativa. Brasília: SDH, 2004.

COSTA, Cláudia Regina Brandão Sampaio Fernandes da; ASSIS, Simone Gonçalves de. Fatores protetivos a adolescentes em conflito com a lei no contexto socioeducativo. Psicol. Soc., Porto Alegre, v. 18, n. 3, p. 74-81, dez. 2006. Disponível em: http://www.scielo.br/scielo.php?script=sci_arttext\&pid =S0102-71822006000300011\& lng=en\&nrm=iso. Acesso em: 27 jan. 2020.

COIMBRA, Cecília Maria Bouças. Operação Rio: o mito das classes perigosas. Niterói, Rio de Janeiro: Intertexto; Oficina do Autor, 2002. Disponível em: https://www.academia.edu/22472174/COIMBRA_ Cec\%C3\%ADlia._Opera\%C3\%A7\%C3\%A3o_Rio_-_o_mito_das_classes_perigosas. Acesso em: 01 abril 2020.

CRUZ, Ana Vládia Holanda. $O$ adolescente em conflito com a lei e a escola: criminalização e inclusão perversa. 2010. 302 f. Dissertação (Mestrado em Psicologia, Sociedade e Qualidade de Vida) Universidade Federal do Rio Grande do Norte, Natal, 2010. Disponível em: https://repositorio.ufrn.br/ jspui/handle/123456789/17447. Acesso em: 15 jan. 2020.

CUNHA, Eliseu; DAZZANI, Maria. A escolarização de adolescentes infratores em um contexto de privação de liberdade. Adolescência e Conflitualidade, São Paulo, n. 14, p. 34-43, 2018. Disponível em: https://revista.pgsskroton.com/index.php/adolescencia/article/view/5162. Acesso em: 10 dez. 2019

DELLECAVE, Michelly; BARBOZA, Camila; CALDERON, Paula. Fatores de risco e proteção para a prática do ato infracional: percepção do adolescente e da família. Adolescência e Conflitualidade, [s. 1.], ano 2018, n. 17, p. 23-39, 2018. Disponível em: https://revista.pgsskroton.com/index.php/adolescencia/ article/view/4713. Acesso em: 10 fev. 2020.

DIAS, Ana Cristina Garcia; ARPINI, Dorian Mônica; SIMON, Bibiana Rosa. Um olhar sobre a família de jovens que cumprem medidas socioeducativas. Psicologia \& Sociedade, v. 23, n. 3), p. 526-535, 2011. Disponível em: http://www.scielo.br/pdf/psoc/v23n3/10.pdf. Acesso em: 02 fev. 2020.

DICIONÁRIO Online de Português. Significado de risco. Porto: 7Graus, 2019. Disponível em: https:// www.dicio.com.br/risco/. Acesso em: 30 jan. 2020. 
DIDONET, Vital. Direitos, infância e agenda pública: ECA 25 anos - primeira infância. In: Blog da ANDI. Direitos, infância e agenda pública. Brasília, 4 ago. 2015. Disponível em: http://blog.andi.org.br/ eca25anos-primeira-infancia-0. Acesso em: 29 mar. 2020.

EISENSTEIN Evelyn. Adolescência: definições, conceitos e critérios. Adolescência Saúde, v. 2, n. 2, p. 6-7, abr./jun. 2005. Disponível em: https://cdn.publisher.gn1.link/adolescenciaesaude.com/pdf/ v2n2a02.pdf. Acesso em: 29 mar. 2020.

FERREIRA, Juliana. $\mathrm{O}$ adolescente e o jovem em conflito com a lei e a escolarização: possibilidade de humanização?. 2015. 132 f. Dissertação (Mestrado em Psicologia) - Universidade Estadual de Maringá, Maringá, 2015. Disponível em: http://repositorio.uem.br:8080/jspui/handle/1/4568. Acesso em: 29 mar. 2020.

FIGUEIREDO, Ivanilda; FRASSETO, Flávio. Medidas socioeducativas: do debate sobre a natureza aos parâmetros legais e aplicação e execução. In: SPOSATO, Karyna. Matriz de formação do Sistema Nacional de Atendimento Socioeducativo. 1ํ. ed. Brasília: UnB, 2015. p. 139-166.

FUCHS, Andréa Márcia S. Lohmeyer. Telhado de vidro: as intermitências do atendimento socioeducativo de adolescentes em semiliberdade. Análise nacional no período de 2004-2008. 2009. 273 f. Tese (Doutorado em Política Social) - Universidade de Brasília, Brasília, 2009. Disponível em: http://www.renade.org.br/midia/doc/tese-andrea-fuchs.pdf. Acesso em: 11 fev. 2020.

GALLO, Alex. Adolescente em conflito com a lei: perfil e intervenção. 2006. 300 f. Tese (Doutorado em Educação Especial) - Universidade Federal de São Carlos. São Carlos, 2006. Disponível em: https:// repositorio.ufscar.br/handle/ufscar/2818?show=full. Acesso em: 10 ago. 2019.

GALLO, Alex; WILLIAMS, Lúcia Cavalcanti de Albuquerque. Adolescentes em conflito com a lei: uma revisão dos fatores de risco para a conduta infracional. Psicol Teoria Prática, v. 7, n. 1, p. 81-95, 2005. Disponível em: http://pepsic.bvsalud.org/pdf/ptp/v7n1/v7n1a07.pdf. Acesso em: 08 jul. 2019.

CODEPLAN: Perfil dos Jovens do Distrito Federal (2018). Brasília: Codeplan; Seplan; Governo do Distrito Federal, 2018. Disponível Em: http://www.codeplan.df.gov.br/wp-content/uploads/2018/02/ Perfil-dos-Jovens-do-Distrito-Federal.pdf. Acesso em: 07 jan. 2020.

IPEA - INSTITUTO DE PESQUISA ECONÔMICA APLICADA. Retratos da desigualdade de sexo e raça. Brasília: Ipea, 2011. Disponível em: https://www.ipea.gov.br/portal/index.php?option=com_cont ent\&view=article\&id=12893\%3Aretrato-das-desigualdades-de-genero-e-raca- $4^{\circ}$ edicao\&catid=266\%3A2 011\&directory=1\&Itemid=1. Acesso em: 01 fev. 2020.

JACCOUD, Luciana. Racismo e república: o debate sobre o branqueamento e a discriminação racial no Brasil. In: THEODORO, Mário. (Org.). As políticas públicas e a desigualdade racial no Brasil. 2. ed. Brasília: Ipea, 2008. cap. 2, p. 19-48. Disponível em: http://www.clam.org.br/bibliotecadigital/uploads/ publicacoes/1107_1899_Livrodesigualdadesraciais.pdf. Acesso em: 01 fev. 2020.

JANCZURA, Rosane. Risco ou vulnerabilidade social?. Textos \& Contextos, Porto Alegre, v. 11, n. 2, ago./dez. 2012, p. 301-308. Disponível em: https://revistaseletronicas.pucrs.br/ojs/index.php/fass/ article/view/12173. Acesso em: 29 nov. 2020.

LEONARDO, Nilza Sanches Tessaro; LEAL, Záira Fátima de Rezende Gonzalez; ROSSATO, Solange Pereira Marques. Estado da arte de estudos sobre a queixa escolar: uma análise a partir da psicologia histórico-cultural. In: LEONARDO, N. S. T. (Org.) ; LeaL, Z.R.G (Org.) ; ROSSATO, S. P. M. (Org.). (Orgs.). Pesquisas em queixa escolar: desvelando e desmistificando o cotidiano escolar. Maringá: Eduem, 2012, p. 15-29. 
LOPES, Geniela. Análise do perfil do adolescente em uma unidade socioeducativa de internação do Paraná. 2012. 76 f. Dissertação (Mestrado Profissional) - Universidade Estadual de Londrina, Londrina, 2012. Disponível em: <encurtador.com.br/jvWX7>. Acesso em: 29 mar. 2020.

YUNES, Maria Angela Mattar; SZYMANSKI, Heloisa. Resiliência: noção, conceitos afins e considerações críticas. Resiliência e Educação. São Paulo: Cortez, 2001, p. 13-42. Disponível em: encurtador.com.br/ xzNT0. Acesso em 30 jan. 2020.

MELO, André Chaves de. Nível de escolaridade e criminalidade se relacionam, afirma estudo. Agência USP de Notícias [online], n. 689/01, 06 de março de 2001. Disponível em: http://www.usp.br/agen/ bols/1998_2001/rede689.htm. Acesso em: 29 nov. 2018.

NARDI, Fernanda; JAHN, Guilherme; DELL'AGLIO, Débora. Perfil de adolescentes em privação de liberdade: eventos estressores, uso de drogas e expectativas de futuro. Psicologia em Revista, Belo Horizonte, v. 20, n. 1, p. 116-137, 2014. Disponível em: http://pepsic.bvsalud.org/pdf/per/v20n1/ v20n1a08.pdf. Acesso em: 31 jan. 2020.

OLIVEIRA, Maria. Criança e adolescente como objeto de violência e exclusão social. Especialização em Políticas Públicas e Socioeducação - ENS. Brasília, 2016. Disponível em: http://www.ens.ceag. unb.br/sinase/ens2/images/Biblioteca/modulos_dos_cursos/Especializa\%C3\%A7\%C3\%A3o/Eixo_2__M\%C3\%B3dulo_3_-_Parte_1.pdf. Acesso em 05 jul. 2019.

OLIVEIRA, Maria Cláudia Santos Lopes de; COSTA, Daniela Lemos Pantoja; CAMARGO, Carolina Knihs de. Infração juvenil feminina e socioeducação: um enfoque cultural e de sexo. Estud. pesqui. Psicol., Rio de Janeiro, v. 18, n. 1, p. 72-92, abr. 2018. Disponível em: http://pepsic.bvsalud.org/scielo. php?script=sci_arttext\&pid=S1808-42812018000100005\&lng=pt\&nrm=iso. Acesso em: 4 jan. 2020.

OLIVEIRA, Maria; SILVA, Samuel; SOUZA, Tatiana. Infância, adolescência, família e sociedade. In: SPOSATO, Karyna. Matriz de formação do Sistema Nacional de Atendimento Socioeducativo. $1^{\circ}$. ed. Brasilia: UnB, 2015. p. 39-74.

PADOVANI, Andréa Sandoval; RISTUM, Marilena. A escola como caminho socioeducativo para adolescentes privados de liberdade. Educ. Pesqui., São Paulo, v. 39, n. 4, p. 969-984, dez. 2013. disponível em: http://www.scielo.br/scielo.php?script=sci_arttext\&pid=S1517-97022013000400010\&ln $\mathrm{g}=$ en\&nrm=iso. Acesso em: 09 abr. 2020.

PEDROZA, Regina. Conceito de desenvolvimento e aprendizagem para uma atuação socioeducativa. Pedagogia Socioeducativa, Brasília, p. 1-26 [Módulo 6]. Disponível em: http://ens.ceag.unb.br/sinase/ ens2/images/Biblioteca/modulos_dos_cursos/Especializacao-Eixo3-Mod6/Eixo-3---Mdulo-6---ParteV--Desenvolvimento-e-aprendizagem-no-campo-socioeducativo.pdf. Acesso em: 02 fev. 2020.

PAES, Paulo Cesar Duarte. Educação de adolescentes privados de liberdade: uma abordagem vigotskiana. Revista Inter Ação, v. 40, n. 2, p. 253-268, 2015. Disponível em: https://doi.org/10.5216/ ia.v40i2.32818. Acesso em 30 dez. 2019.

PEREIRA, Thamyris Cristina; REIS, Jhonatan Natércio dos; COSTA, Luciana Assis. Autor e vítima: a vulnerabilidade social. Revista Terapia Ocupacional, v. 26, n. 2, p. 258-266.maio/ago. 2015. Disponível em: https://www.revistas.usp.br/rto/article/view/74957/101733. Acesso em: 23 jan. 2020.

RABESCHINI, André. Crime e contravenção penal: diferenças e semelhanças. In: Âmbito Jurídico. São Paulo, 2014. Disponível em: https://ambitojuridico.com.br/cadernos/direito-penal/crime-econtravencao-penal-diferencas-e-semelhancas/. Acesso em: 23 jan. 2020. 
RIZZINI, Irene; RIZZINI, Irma. A institucionalização de crianças no Brasil: percurso histórico e desafios do presente. Rio de Janeiro: PUC-Rio, 2004. Disponível em: http://www.editora.pucrio.br/ media/ebook_institucionalizacao_de_criancas_no_brasil.pdf. Acesso em: 30 dez. 2019.

SANTOS, Érica Piedade dos. (Des)construindo a 'menoridade': uma análise crítica sobre o papel da Psicologia na produção da categoria “menor”. In: GONÇALVES, Hebe Signorini; BRANDÃO, Eduardo Pontes. (Orgs). Psicologia jurídica no Brasil. Rio de Janeiro: Nau, 2004, p. 205-248.

SIERRA, Vânia. Ressocialização ou socioeducação? Perspectivas ao adolescente em cumprimento de medidas socioeducativas. In: MENDES, Cláudia C. (Org.). Trajetória de vida violência e vulnerabilidade. Rio de Janeiro: DEGASE, 2019, p. 184-198. Disponível em: https://www.academia. edu/40511303/Trajetoria_de_vida_violencia_e_vulnerabilidade_digital_1_p\%C3\%A1ginas_1_10_. Acesso em: 15 fev. 2020.

SIERRA, Vânia Morales; MESQUITA, Wania Amélia. Vulnerabilidades e fatores de risco na vida de crianças e adolescentes. São Paulo em Perspectiva, São Paulo, Fundação Seade, v. 20, n. 1, p. 148-155, jan./mar. 2006. Disponível em: http://produtos.seade.gov.br/produtos/spp/v20n01/v20n01_11.pdf. Acesso em: 02 fev. 2020.

SILVA, Roberto da. Os filhos do governo: a formação da identidade criminosa em crianças órfãs e abandonadas. São Paulo: Ática: 1997.

SOUZA, Tatiana Yokoy de; OLIVEIRA, Maria Cláudia Lopes de; RODRIGUES, Dayane Silva. Adolescência como fenômeno social. Contextualização socioeconômica das adolescências brasileiras. In: BISINOTO, Cynthia. (Org.). Docência na Socioeducação. Brasília: Faculdade UnB Planaltina; Universidade de Brasília, 2014, p. 119-145. Disponível em: https://docenciasocioeducacaounb.wordpress.com/sobre/ material-livros/. Acesso em: 10 jan. 2020.

SOUZA, TATIANE. Adolescência e juventude: questões contemporâneas. Brasília: Escola Nacional de Socioeducação, 2016. Disponível em: http://ens.ceag.unb.br/sinase/ens2/images/Biblioteca/modulos dos_cursos/Nucleo_Basico_2015/Eixo_1/EixoI.pdf. Acesso em: 12 de fev. 2020.

SPOSITO, Marília Pontes; CARRANO, Paulo César Rodrigues. Juventude e políticas públicas no Brasil. Rev. Bras. Educ., Rio de Janeiro, n. 24, p. 16-39, dez. 2003. Disponível em: http://www.scielo. br/scielo.php?script=sci_arttext\&pid=S1413-24782003000300003\&lng=en\&nrm=iso. Acesso em 30 mar. 2020.

ZAPPE, Jana Gonçalves; RAMOS, Nara Vieira. Perfil de adolescentes privados de liberdade em Santa Maria/RS. Psicologia \& Sociedade, v. 22, n. 2, p. 365-373, 2010. Disponível em: https://www.scielo.br/ pdf/psoc/v22n2/17.pdf. Acesso em: 30 mar. 2020. 